\title{
Prevalence of Repeat Breeding Syndrome in Dairy Cattle in Selected Regions of Kenya
}

\author{
Edward N Njoroge ${ }^{1 *}$, Henry M Mutembei ${ }^{1}$, Ambrose N Kipyegon ${ }^{1}$, Peter Kimeli $^{1}$ and Moses O Olum ${ }^{2}$ \\ ${ }^{1}$ Clinical Studies Department, Faculty of Veterinary Medicine, University of Nairobi, Nairobi, Kenya; ${ }^{2}$ Kenya \\ Agricultural and Livestock Research Organization (KALRO), Veterinary Science Research Institute, Muguga North, \\ Kikuyu, Kenya \\ *Corresponding author: edwarq32@gmail.com
}

\begin{tabular}{l} 
Article History: $20-117 \quad$ Received: $12-$ May-20 Revised: $10-A u g-20$ \\
\hline ABSTRACT \\
The optimum production in dairy cows aims at getting a calf per cow per year. This, however, is limited by repeat \\
breeding syndrome (RBS), which has multiple etiologies that cause either fertilization failure or early embryonic \\
death. This study objective was to determine the prevalence of repeat breeding syndrome in dairy cattle within the \\
selected regions of Kenya. A cross-sectional study design was carried out in 205 smallholder dairy farms in Makueni, \\
Kakamega and Nandi counties. A total of 553 cows/heifers were recruited and examined per rectal to determine their \\
reproductive status. Information on the breeding history of the cow and heifer was acquired at the farm. The results \\
revealed that cross bred cattle were most affected by RBS at $38.9 \%$ followed by Jersey, Guernsey Ayrshire and least \\
in Frisians at $21.1,16.7,25$ and $14 \%$, respectively. The overall animal level prevalence of RBS in cattle in the three \\
counties was at $18.4 \%$, while the overall farm-level prevalence was $58.3 \%$. However, per county prevalence's were \\
different with animal level prevalence at $31.9,20.9$ and $12.5 \%$ in Makueni, Kakamega and Nandi, respectively. The \\
farm-level prevalence's at the counties were $75.4,58.3$ and $48.4 \%$ in Makueni, Kakamega and Nandi counties, \\
respectively. Cattle kept in the zero-grazing/intensive system had the highest level of RBS at $30.1 \%$ compared to \\
semi-intensive and extensive farming systems. The prevalence of RBS was also higher in multipara at $76 \%$ in \\
comparison to primipara cows. Finally cows over four years which were in third or more parities had the highest \\
prevalence of RBS, accounting for $65 \%$ of the cases. In conclusion, the prevalence of RBS is significantly high in the \\
Kenyan smallholder dairy farms. Further research should be undertaken to identify risk factors and appropriate \\
intervention approaches for RBS to enhance its management.
\end{tabular}

Key words: Kenyan, Exotic, Cattle, Repeat-breeding, Prevalence.

\section{INTRODUCTION}

The smallholder dairy industry is a significant sector in Kenya as it contributes $3.5 \%$ of the Kenyan Gross Domestic Product (GDP), which accounts for $21 \%$ of the $40 \%$ from agricultural produce (Knechtges 2011). The smallholder dairy farming makes up $80 \%$ of the dairy population; therefore, a crucial driver for rural development, poverty reduction and food and nutrition security (Bingi and Tondel 2015; Olum et al. 2020). The dairy farming enterprise is, however, constrained by infertility-related factors, among them repeat breeding syndrome (RBS) (Mungube et al. 2019). Repeat breeding syndrome is a condition in which a clinically normal cow which is less than eight years old fails to conceive after three regularly spaced inseminations (Yusuf et al. 2010).
The RBS is shown to be a multi-etiological problem as described in (Pérez-Marín and Espana 2007). The standard index for services per conception is an average of 1.5 rounded off to the nearest whole number of 2 services per conception (Radostits et al. 2001). Repeat breeding syndrome contributes to sub-optimal production and economic loss in the dairy industry through; delayed conception, maintaining a low productive or nonproductive state, increased number of services per conception, increased inter-calving interval and culling rate which reduces the number of calves per cow in a lifetime (Ahmadi and Dehghan 2007; Nishi et al. 2018). Although bovine RBS has been studied widely in other countries; the literature is limited in Kenya's smallholder dairy farms. The current study, therefore, aimed at estimating the prevalence of RBS in dairy cattle within the selected counties of Kenya.

Cite This Article as: Njoroge EN, Mutembei HM, Kipyegon AN, Kimeli P and Olum MO, 2021. Prevalence of repeat breeding syndrome in dairy cattle in selected regions of Kenya. International Journal of Veterinary Science 10(2): 114118. https://doi.org/10.47278/journal.ijvs/2020.019 


\section{MATERIALS AND METHODS}

\section{Study Area and Approval}

The study was conducted in 3 counties with different agro-ecological and social-economic activities, and a high presence of dairy breeds with a high level of artificial insemination (AI) uptake. These counties were; Nandi, Kakamega and Makueni, from which nine subcounties were purposively selected. The subcounties were Chesumei, Nandi Hills and Mosop in Nandi county; Lurambi, Mumias West and Likuyani in Kakamega county and; Makueni, Mbooni and Kaiti in Makueni county.

This study was approved by the Kenya Agricultural and Livestock Research Organization (KALRO), Veterinary Science Research Institute (VSRI) Institutional Animal Care and Use Committee (IACUC) and assigned the approval number KALRO/VSRI/ IACUC/2/20172019.

\section{Study Design}

This was a cross-sectional study in which farm visits and animal examinations were conducted once during the study period. The study was carried out between December 2018 and June 2019 during which 205 farms were visited, and 553 cattle examined.

\section{Farm, Animal Selection and Sample Size}

A list of smallholder farmers in the study area was obtained from existing dairy cooperative records. Computer-generated random numbers were used to identify the farms to participate in the study. Smallholder dairy farm was defined as that with 1-15 animals: the average herd size being 1-3 animals in rural areas and 7-8 dairy animals in urban and peri-urban areas (Njarui et al. 2011; SNV 2015).

All mature female animals above two years of age that had been mated in the last one year were included in the study.

The prevalence of RBS in Kenya at the time of this study was unknown and therefore, calculation of sample size was done through an estimated prevalence of $50 \%$, a precision of 5\% and confidence level at 95\% (Dohoo et al. 2009).

$$
\begin{gathered}
\mathrm{n}=\frac{(1.96)^{2} \times \mathrm{P}^{2}}{\mathrm{~L}^{2}} \\
\mathrm{n}=\frac{(1.96)^{2} \times(0.5)^{2}}{(0.05)^{2}}
\end{gathered}
$$

$\mathrm{n}=385$ cows.

$\mathrm{n}$ - being the minimum sample size for this study.

\footnotetext{
Methodology

The study subjects were rectally examined to confirm the reproductive status to help categorize the cow as a repeat or non-repeat breeder. The breeding records were scrutinized and where non available farmers recall was utilized to gather crucial data. The reproductive history was also acquired with emphasis to the number of services per conception. Subjects served three or more times with or without conception were defined as repeat breeders.
}

\section{Data Management}

The data collection which included all aspects of breeding management and history as well as animal level as well as farm level factors was conducted using epicollect+ mobile application and then retrieved into Microsoft excel 2010 sheets. Data was thereafter scrutinized for accuracy and errors and then coded and finally imported to Stata ${ }^{\circledR} 15$ software for analysis. Proportion of RBS at farm and animal-level was calculated to determine its prevalence. Additionally, the proportions were computed for different categories.

\section{RESULTS}

A significantly higher percentage $(60 \%)$ of dairy cattle in this study was bred using Artificial insemination (AI) while $40 \%$ were bred using natural service. The regional variations in the breeding methods were as follows: In Makueni $87 \%$ of dairy cows was bred through strict AI while the rest $13 \%$ heavily relied on NS. In Kakamega County a significantly higher percentage $(68 \%)$ of dairy cattle were bred through AI while the rest $32 \%$ used NS. In Nandi County the lowest percentage $(25 \%)$ of dairy cows were bred using AI while the rest $(75 \%)$ relied heavily on NS.

Repeat breeder syndrome was observed across the counties with an overall animal level prevalence of $18.44 \%$. The overall farm level prevalence of RBS across the counties was significantly higher at $58.3 \%$. Makueni County reported an animal level prevalence of $31.96 \%$ (22/69), followed by Kakamega at $20.85 \%$ (15/72) and Nandi $12.5 \%$ (8/64). The farm-level prevalence at the county was $75.4 \%(52 / 69), 58.3 \%(42 / 72)$ and $48.4 \%$ (31/64) in Makueni, Kakamega and Nandi counties respectively.

Repeat breeding syndrome prevalence was highest among the crossbred cow/heifers at 38.9\% (14/36) followed by Jersey, Ayrshire, Guernsey and least in Friesians at $25 \%(2 / 8), 21.1 \%$ (43/204), 16.7\% (2/12) and $14.0 \%$ (41/293) respectively. The type of production system affected RBS prevalence with the highest among the zero grazed animals at $30.1 \%$ (22/73) followed by semi-intensive and extensive grazing systems at $20 \%$ $(14 / 70)$ and $14.5 \%(9 / 62)$ respectively.

The level of awareness of RBS within the smallholder dairy was high, with $64.39 \%(132 / 205)$ of farmers aware of the condition against $35.6 \%(73 / 205)$ of farmers who were unaware of RBS in dairy cows. The highest proportion of this condition was seen in farmers with a secondary level of education $40 \%(82 / 205)$ and least with those having tertiary education $20 \%(9 / 205)$.

Repeat breeding syndrome prevalence was highest in multipara cows at $76 \%(78 / 102)$ in comparison with heifers at $24 \%$ (24/102). Similarly, the prevalence of this syndrome was higher in older cows with cows at 4 years accounting for $20 \%$ (20/102) while cows over four years accounting for $65 \%(67 / 102)$ of RBS cases. There was an association between age at first service and repeat breeder syndrome, the cows with RBS had a slightly higher (27.37 months) age at first service as compared to the non-repeat breeder cows at 25.98 months. Furthermore, cows with RBS were served earlier at 3.5 months on average postpartum as compared to non-repeat breeder cows served at 3.58 months postpartum. 
Int J Vet Sci, 2021, 10(2): 114-118.

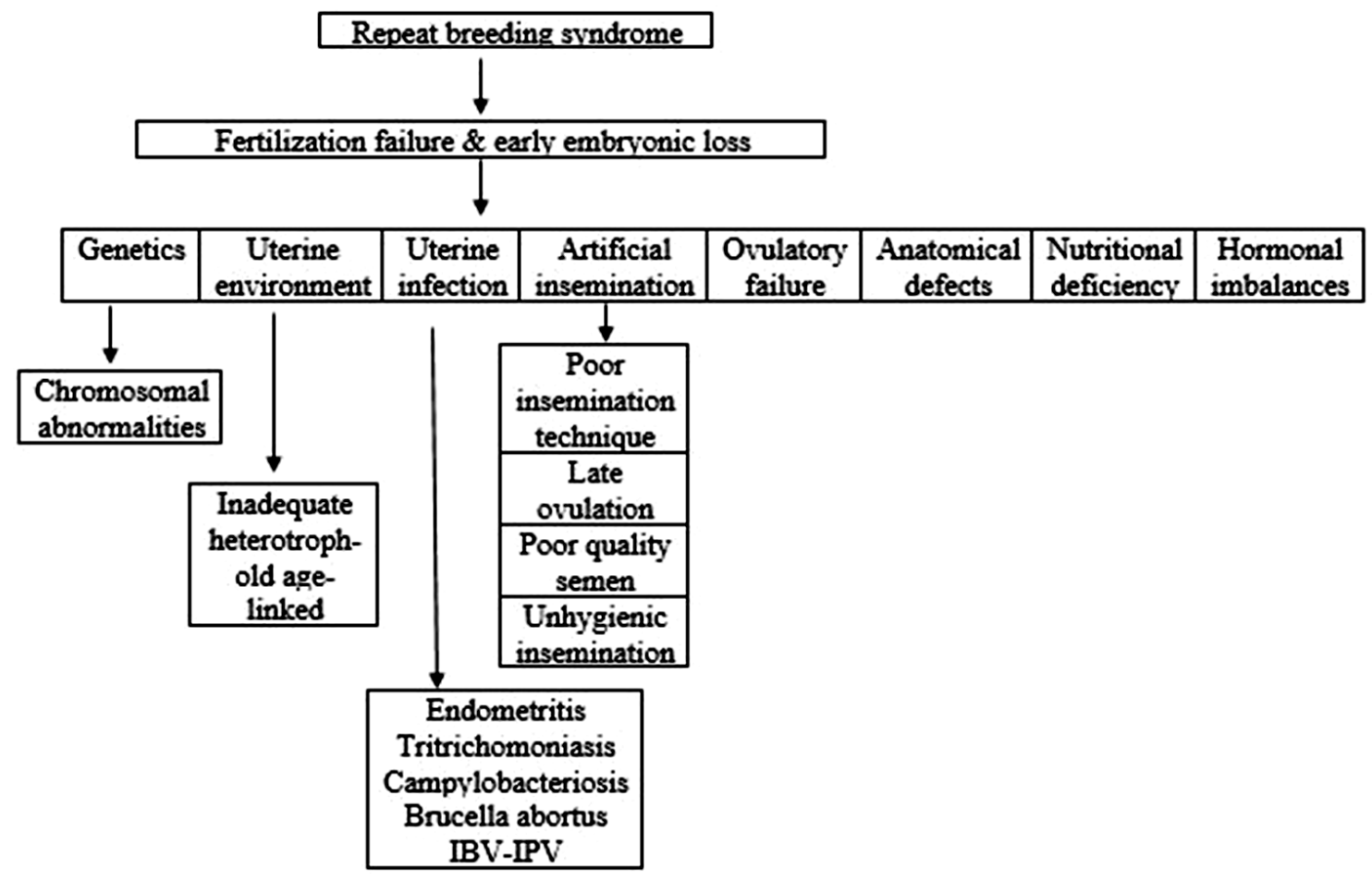

Fig. 1: Schematic etiological factors of repeat breeding syndrome (Rodriguez et al. 2000; Morrell 2006; Thakur et al. 2006; PérezMarín and Espana 2007; Bazer et al. 2009; Santos et al. 2009; Jaswal and Singh 2010).

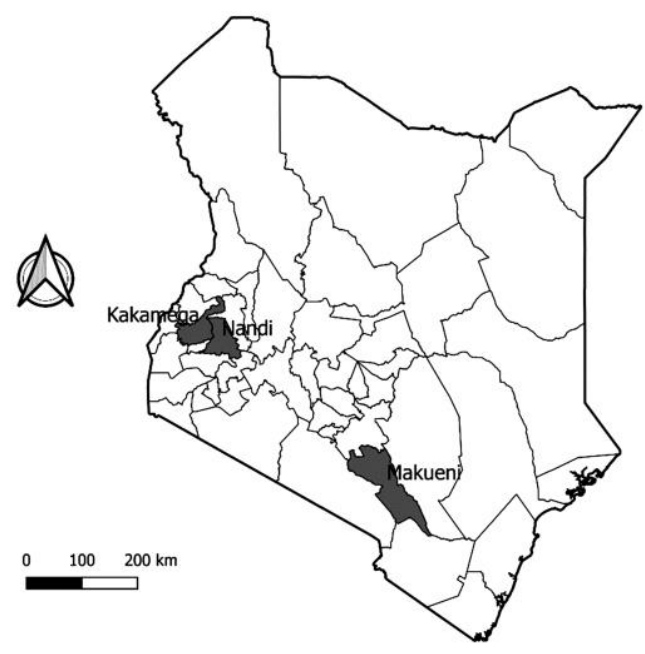

Fig. 2: Map of Kenya showing study counties.

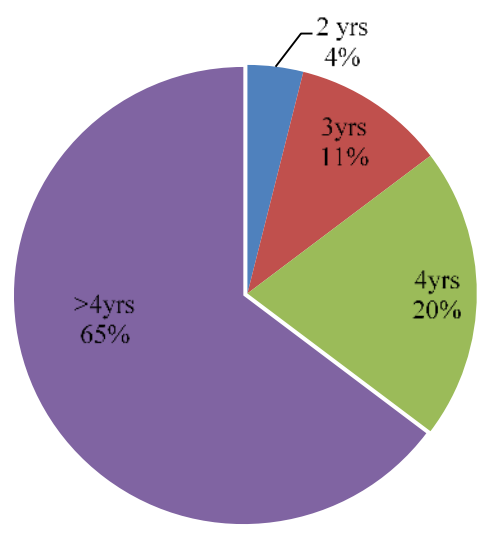

Fig. 3: Proportion of RBS within different age in cows/heifers in the small-scale dairy farms in the counties of Makueni, Kakamega and Nandi counties during the study between Dec 2018-Jun 2019.

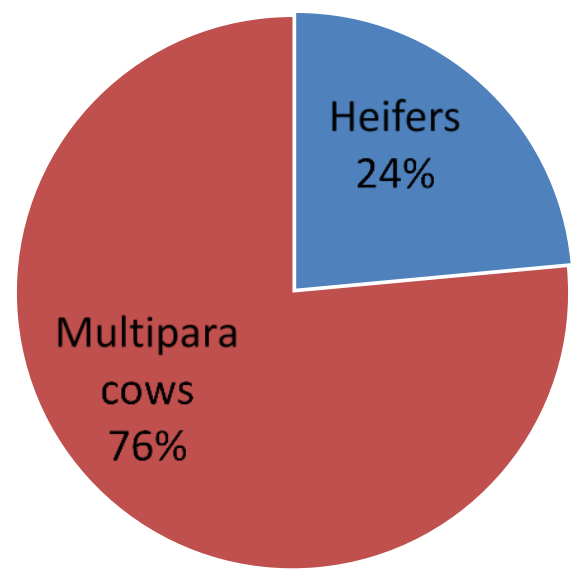

Fig. 4: Comparison of proportion of RBS in cows against heifers in the small-scale dairy farms in the counties of Makueni, Kakamega and Nandi during the study done between Dec 2018Jun 2019.

\section{DISCUSSION}

This study documents the existence of RBS within the smallholder dairy farms of Makueni, Kakamega and Nandi counties of Kenya and the situation could be similar in a majority of smallholder farms in Kenya.

In the current study, the smallholder dairy farmers had a preference for Friesians, Ayrshires and their crosses over other breeds of cattle. The findings of this study are similar to the findings of Mugambi et al. (2015).

The overall prevalence of RBS was $18.44 \%$ and $58.13 \%$ in animal and farm level prevalence, respectively, which is higher than what was reported by Ayalon (1984). Other studies have shown a lower or higher prevalence in comparison to the findings of this study (Bage et al. 2002; Boettcher and Parera 2007; Asaduzzaman et al. 2016). 
Table 1: Proportion of RBS against various factors of study

\begin{tabular}{llcr}
\hline Variable & Category & Distribution & $\begin{array}{l}\text { Proportion } \\
\text { with RBS (\%) }\end{array}$ \\
\hline Animal level RBS & Repeat breeder & 102 & $102(18.44)$ \\
& Non repeat breeder & 451 & $451(81.56)$ \\
Farm level RBS & Repeat breeder & 119 & $119(58.3)$ \\
& Non repeat breeder & 86 & $86(41.95)$ \\
Breed & Friesian & 293 & $41(14.0)$ \\
& Guernsey & 12 & $2(16.7)$ \\
& Ayrshire & 204 & $43(21.1)$ \\
Pregnancy status & 8 & $2(25)$ \\
Level of education & Nersey & 36 & $14(38.9)$ \\
& Crosses & 381 & $88(23.1)$ \\
& Primary & 172 & $14(8.1)$ \\
Type of grazing & 78 & $15(19.2)$ \\
system & Secondary & 82 & $21(25.6)$ \\
& Tertiary & 45 & $9(20.0)$ \\
Awareness of & Sero grazing & 73 & $22(30.1)$ \\
RBS & Extensive & 70 & $14(20.0)$ \\
& Aware & 62 & $9(14.5)$ \\
& Unaware & 132 & $35(26.5)$ \\
& & 73 & $10(13.7)$ \\
\hline
\end{tabular}

The variations in these results may be due to geographical location, agro-climatic zones, parameters used to define RBS and the prevailing aetiologies (Ali et al. 2006). In this study the possible causes of RBS could be due to fertilization failures due to flaws in $\mathrm{AI}$ as RBS prevalence was higher in region using AI in comparison with NS.

There was variation in the prevalence of RBS within the different study regions, with the highest prevalence (31.96 and $75.71 \%$ for the animal and farm-level, respectively) noted in Makueni along with the highest strict adoption of AI (87\%). Kakamega county had the second-highest prevalence (20.8 and $58.11 \%$ for animal and farm level respectively) along with the second-highest artificial insemination (AI) adoption rate at $68 \%$. The lowest prevalence of RBS (12.5 and $48.75 \%$ for animal and farm level, respectively) was noted in Nandi county, which also had the lowest adoption of AI $(25 \%)$. These findings indicate an association between $\mathrm{AI}$ as a breeding method and RBS. Notably, farms using natural service as opposed to farms using AI had lower incidences of RBS; this is similar to reports by Jainudeen and Hafez (2000). Additionally, when AI is used, the wrong timing of insemination may lead to an increased proportion of RBS (Shamsuddin et al. 2001).

This study noted out that the majority $(65 \%)$ of RBS was common in cows greater than four years of age which were cow in third or more parity. According to Gustafsson and Emnuelson (2002), RBS was more common in cows $>7$ years which is higher than that observed, the difference in findings could be due to the difference in the agro-ecological zones and management at the farms where the studies were conducted. However, Sarder et al. (2010) reported lower RBS in cows <4 years of age, which is in agreement with the findings of this study. Therefore, older cows are more prone to RBS to a higher degree than younger cows.

Majority of cattle $(76 \%)$ with RBS were multipara with only $24 \%$ of them being heifers. This report is in agreement with an earlier report by Mandefro and Negash (2014) who found out that $22.64 \%$ of heifers had RBS. The same report by Mandefro and Negash (2014) also found that the highest $(22.22 \%)$ RBS cases among cows in third calving while the lowest $(7.24 \%)$ at first calving. This is consistent with the study findings. The overall result is in agreement with the wide documentation of the negative effect of age on fertility (Hodel et al. 1995). The lower fertility with old age could be due to variation in the pituitary or hypothalamic hormone levels or the different ability of ovarian response in the different ages of the cows.

\section{Conclusion}

This study documents the presence of RBS within the small-scale dairy farms of Kenya. As such, this study has shown that RBS is a major hindrance to the optimization of dairy production in the small-scale dairy farms of Kenya. Further research should be undertaken to identify risk factors and appropriate intervention approaches for RBS to enhance its management.

\section{Acknowledgement}

The author acknowledges the financial support received from KALRO and Director-General KALRO for approving the project and the management of KALRO VSRI Muguga for their timely logistical support. In addition, special gratitude goes to the extensive teams from farm identification, farmers, data collection and data analysis.

\section{Author's contribution}

All authors equally contributed to this study.

\section{REFERENCES}

Ahmadi MR and Dehghan SA, 2007. Evaluation of the treatment of repeat breeder dairy cows with uterine lavage plus PGF2 $\alpha$, with and without cephapirin. Turkish Journal of Veterinary and Animal Sciences 31: 125-129.

Ali RIASAT, Raza MA, Jabbar Abdul and Rasool MH, 2006. Pathological studies on reproductive organs of Zebu Cow. Journal of Agriculture \& Social Sciences 2: 91-95.

Asaduzzaman KM, Bhuiyan MMU, Rahman MM and Bhattacharjee J, 2016. Prevalence of repeat breeding and its effective treatment in cows at selected areas of Bangladesh. Bangladesh Journal of Veterinary Medicine 14: 183-190.

Ayalon N, 1984. The repeat breeder problem in 10 international congress an animal reproduction and artificial insemination, University of Illinois at Urbana-Champaign (USA), 10-14 Jun 1984 University of Illinois at Urbana-Champaign.

Båge R, Gustafsson H, Larsson B, Forsberg M and RodriguezMartınez H, 2002. Repeat breeding in dairy heifers: follicular dynamics and estrous cycle characteristics in relation to sexual hormone patterns. Theriogenology 57 : 2257-2269. https://doi.org/10.1016/S0093-691X(02)00840$\underline{3}$

Bazer FW, Spencer TE, Johnson GA, Burghardt RC and Wu G, 2009. Comparative aspects of implantation. Reproduction 138: 195-209. https://doi.org/10.1530/REP-09-0158

Bingi S and Tondel F, 2015. Recent developments in the dairy sector in Eastern Africa European Centre for Development Policy Management, Briefing Note, 78.

Boettcher PJ and Perera BMAO, 2007. Improving the reproductive management of smallholder dairy cattle and the effectiveness of artificial insemination: a summary Improving the Reproductive Management of Dairy Cattle Subjected to Artificial Insemination, Vienna, pp: 1-8.

Dahoo PR, Bertaux JL, Montmessin F, Villard E, Vandaele AC and Teffo JL, 2009. March Simulated spectra of CO2 isotopologues to analyze observation from MARS and VENUS 
Gustafsson H and Emanuelson U, 2002. Characterisation of the repeat breeding syndrome in Swedish dairy cattle. Acta Veterinaria Scandinavica 43: 115.

Hodel F, Moll J and Kunzi N, 1995. Factor affecting fertility in cattle. Schweizer Fleckvieh 4: 14-24.

Jainudeen MR and Hafez ESE, 2000. Cattle and Buffalo: Chapter 11. In: Reproduction in Farm Animals, B. Hafez B and Hafez ESE (eds), $7^{\text {th }}$ Ed., John Wiley \& Sons, Inc. pp: 157-171. https://doi.org/10.1002/9781119265306.ch11

Jaswal RS and Singh M, 2010. Effect of administration of Buserelin acetate on different days of estrous cycle on conception in repeat breeder dairy cows. The Blue Cross Book 25: 48-51.

Knechtges PL, 2011. Food safety: Theory and practice Jones \& Bartlett Publishers.

Mandefro M and Negash, G, 2014. Repeat breeder syndrome in dairy cows: influence of breed and age on its prevalence. World Journal of Agricultural Sciences 10: 200-203.

Morrell JM, 2006. Update on semen technologies for animal breeding. Reproduction in Domestic Animals 41: 63-67. https://doi.org/10.1111/j.1439-0531.2006.00621.x.

Mugambi DK, Mwangi M, Wambugu SK and Gitunu AMM, 2015. Assessment of performance of smallholder dairy farms in Kenya: an econometric approach. Journal of Applied Biosciences 85: 7891-7899.

Mungube EO, Njarui DMG, Maichomo MW, Olum MO, Ndirangu PN, Kabirizi J, Ndikumana J and Mwangi G, 2019. Reproductive performance indicators of dairy cattle in selected small-scale dairy farms in semi-arid Eastern Kenya. Livestock Research for Rural Development 31: Article \# 88

Nishi SA, Sarder MJU, Islam MH, Kamruzzaman SM, Islam MA and Khaton R, 2018. Factors affecting the incidence of repeat breeding in dairy cows in Rajshahi district, Bangladesh. International Journal of Livestock Research 8: 90-96. https://doi.org/10.5455/ijlr.20171218102335

Njarui DMG, Gatheru M, Wambua JM, Nguluu SN, Mwangi DM and Keya GA, 2011. Feeding management for dairy cattle in smallholder farming systems of semi-arid tropical Kenya. Livestock Research for Rural Development, 23(05). http://wwwlrrdorg/lrrd23/5/njar23111htm
Olum MO, Mungube EO, Nakami WN, Kidali JA, Njenga EN, Maichomo MW, Tsuma VT and Mugambi JM, 2020. A cross-sectional study on infertility and its causes in small holder dairy cattle in selected counties of Kenya International Journal of Veterinary Science 9: 534-539. https://doi.org/10.37422/IJVS/20.079

Pérez-Marín CC and Espana F, 2007. Oestrus expression and ovarian function in repeat breeder cows, monitored by ultrasonography and progesterone assay. Reproduction in Domestic Animals 42: 449-456. https://doi.org/10.1111/ j.1439-0531.2006.00805.x.

Radostits OM, Leslie KE and Fetrow J, 2001. Herd Health Animal Production Medicine, $3^{\text {rd }}$ Ed, WB Saunders Company Philadelphia.

Rodriguez LAM, Lozano CB and Pérez VJE, 2000. La translocaciónrobertsoniana $1 / 29$ en ganadovacuno: susconsecuencias en la reproducción SaludPúbl Nutrición, 2.

Santos JEP, Rutigliano HM and Sá Filho MF, 2009. Risk factors for resumption of postpartum estrous cycles and embryonic survival in lactating dairy cows. Animal Reproduction Science 110: 207-221. https://doi.org/10.1016/j. anireprosci.2008.01.014

Sarder MJU, Moni MJZ and Aktar S, 2010. Prevalence of reproductive disorders of crossbred cows in the Rajshahi District of Bangladesh. SAARC Journal of Agriculture 8: 65-75.

Shamsuddin M, Bhuiyan MMU, Sikder TK, Sugulle AH, Chanda PK, Alam MGS and Galloway D, 2001 Constraints limiting the efficiency of artificial insemination of cattle in Bangladesh (No IAEA-TECDOC--1220).

SNV, 2015. The Kenya Market-Led Dairy Programme (KMDP) http://wwwsnvorg/public/cms/sites/default/files/explore/ download/kenya_marketled_dairy_programme_status_rep ort nov 2015pdf

Yusuf M, Nakao T, Ranasinghe RBK, Gautam G, Long ST, Yoshida C, Koike K and Hayashi A, 2010. Reproductive performance of repeat breeders in dairy herds. Theriogenology 73: 1220-1229. https://doi.org/10.1016/ j.theriogenology.2010.01.016. 